www.jmscr.igmpublication.org

Impact Factor (SJIF): 6.379

Index Copernicus Value: 71.58

ISSN (e)-2347-176x ISSN (p) 2455-0450

crossref DOI: _https://dx.doi.org/10.18535/jmscr/v6i4.147

Journal Of Medical Science And Clinical Research

\title{
Petit's Lumbar Hernia- a Double Layer Technique for Tension Free Mesh Repair
}

\author{
Authors \\ Sanjay Kujur MS FAIGES, Jeetendra Ku Sahu MS, Prof A N Behera MS FAIS \\ FAIGES, Harish Ch Dhamudia MS, Kishan Soni PG
}

\begin{abstract}
Since De Garengoet described first incarcerated hernia in 1731 Lumbar Hernia is relatively rare case, fewer than 300 cases reported in the literature. It occurs through the postero-superior lumbar triangle (Grynfeltt's) and less commonly in the inferior lumbar triangle (Petit's) ${ }^{[1]}$. Surgical treatment is recommended because of the risk of entrapment and strangulation [4].the incidence rate is less than 1.5\% among all hernia cases ${ }^{[2]}$. patient with lumbar hernia can present with flank bulge accompanying with local discomfort and tenderness ${ }^{[3]}$. There are several treatments as per the facial defect ${ }^{[4]}$. For small defect direct approximation of muscle is sufficient. For larger defect facial flap or mesh fixation is essential $\{4,5$, and 6\}. Nowadays laparoscopic Transabdominal extra peritonial repair of lumbar hernia is ideal ${ }^{[7]}$.

Keywords: Onlay Mesh, Superior Lumbar Triangle (Grynfeltt), Inferior Lumbar Triangle (Petit's Triangle), Sublay Mesh, Anterior Approach, Laparoscopic Repair, Preperitoneal Space.
\end{abstract}

\section{Case Report}

A 60 yrs old male patient presented to the Surgery Department of VIMSAR Burla on 19.11.15 with a left side swelling of 6 month. He had history of (H/o) viral fever with herpes zoster (HZ) on left subcostal region about 1 yr back. After 6 month he noticed a swelling on left flank which enlarged progressively causing local discomfort. He had no H/o trauma, previous surgery and lifting heavy weight. On examination there was a round soft non tender swelling about $10 \mathrm{~cm}$ in diameter above the left iliac bone on left flank. It was reducible with visible and palpable cough impulse the bulge above iliac crest is more marked during valsalve manoeuvre; it was reducible by manipulation with no sigh of strangulation and not possible to delimit the hernial ring.
Ultrasonography shows defect in abdominal wall on left postero-lumbar region with defect of $5.5 \times 5.0 \mathrm{~cm}$ and herniation of small intestine and adipose tissue with this diagnosis Of Petit's Dorsal Hernia and surgical treatment was recommended. CT scan was not done as a CT scan facility was not available. So based on clinical findings and Ultrasonography diagnosis was confirmed.

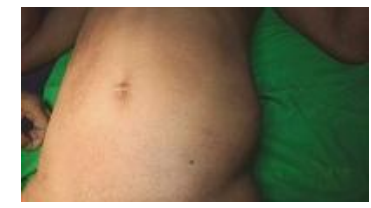

Figure 1 lumbar hernia

\section{Surgical Technique}

Patient was placed in right lateral position; a transverse incision was made $7 \mathrm{~cm}$ above the left 
iliac crest approximately and along the paraspinal musculature. Subcutaneous dissection revealed a large hernial sac protruding on the lower portion of latissimus dorsi muscle. The sac was superior to the edge of iliac crest and medial to the external oblique muscle.

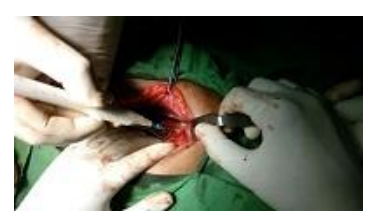

Figure 2 hernial sac dessection

The hernial sac was completely dissected from its limit and reduced. A preperitoneal plane was created without harming the sac just below the muscle that delimits the petit's triangle. A Polypropylene Mesh was inserted in this space and it was fixed to the external oblique muscle and latissimus dorsi muscle with 2/0 polypropylene fixing stitches (SUBLAY MESH).

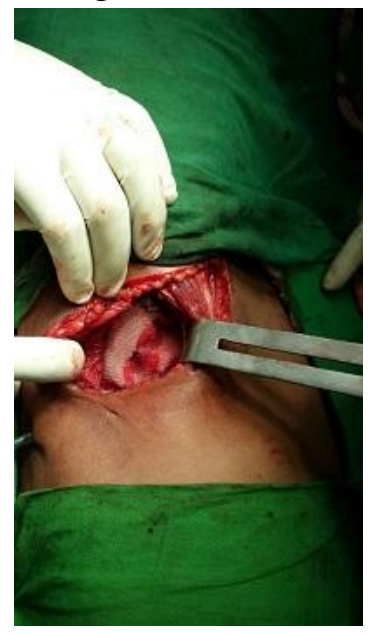

Figure 3 Sublay mesh placement

The edges of Petit's Triangle were then brought together to reduce the hernia defect. Then another mesh was put on the muscle i.e. ONLAY MESH whish was stitched to iliac crest on layers, limited by several stitches.

A suction drain was left in subcutaneous position. The wound was closed with intradermal stitches to skin and pressure dressing was applied, drain removed on $2^{\text {nd }}$ postoperative day and patient was discharged on 3rd postoperative day. The patient was followed till date without complication on healing of wound.

On latest check-up after 2 years; the appearance was satisfactory and there was no recurrence. The patient has remained asymptomatic without hampering his daily activities.

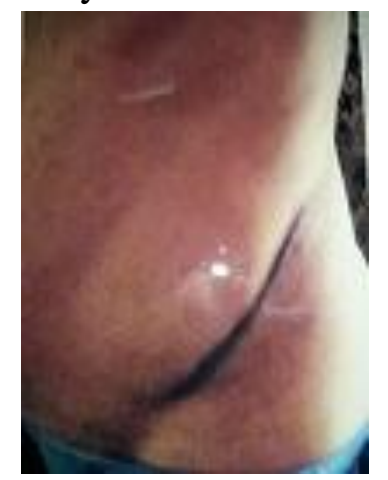

Figure 4 post op 2 yrs later

\section{Discussion}

Lumbar Hernia can be subdivided into 2 categories: Congenital and Acquired, the later type is more common which may be primary and secondary sub category. This article presented a hernia of the lumbar lower triangle which is secondary and acquired. Because he had h/o HZ on left flank most probably 12 intercostals nerve had led to motor neuron paralysis. There are reports of cases of $\mathrm{HZ}$ infection leading to lumbar hernia due to muscle weakness.

Some authors ${ }^{[8,9]}$ had argument that surgical treatment of lumbar hernia should be based on the size of defect. Surgery is indicated in small defect, the repair of hernia should follow the trend of inguinal hernia like open tension free mesh repair i.e. on extraperitonial space as like laparoscopy. The laparoscopic repair is namely Transabdominal Partial Extraperitonial (TAPE) technique ${ }^{[10,11 .]}$. After destruction of the orifice of triangle it becomes 3 dimensional spaces. The Sublay mesh should cover the entire defect and the distal limit should be at least 5 comes that it will protect the muscle and intramuscular spaces. Some authors agree that the intra abdominal pressure is enough to hold the mesh in space which obeys the principle of Pascal ${ }^{[12.13]}$

As an alternative Carbonel et al ${ }^{[14]}$ presented the use of bone anchoring fixation by using Onlay mesh covering the defect crossing the edge of the iliac crest. But it causes postoperative pain in some cases. 


\section{Conclusion}

We proposed Petit's Triangle Lumbar Hernia with a tension free repair by placement of two layer mesh. Sublay mesh placement is very important as like laparoscopy (TAPE).the another Onlay mesh placement increases protection on the lower edge of iliac crest whose placement is required in larger defect. It avoids separation of muscle from the triangle. HZ infection involving 12 intercostals nerve of left side may lead to weakness of the muscle and lead to lumbar hernia formation.

\section{Reference}

1. Wakhlu A, Wakhlu AK, Congenital Lumbar Hernia Paediatric Surg Int. 2000; 16(1-2):146-8 Pub med.

2. Bickel A, Haj M, Eitan A. Laparoscopic management of lumbar hernia. Surg Endosc. 1997; 11(11):1129-1130 [Pub Med]

3. Kawashita Y, Iwata T, Kanetaka K, Ono S, Matsuo M, Nagayoshi S, Kanematsu T. Successful laparoscopic repair of a lumbar hernia occurring after iliac bone harvest. Surg Laparosc Endosc Percutan Tech. 2010 Feb; 20(1):e38-41. doi: 10.1097/SLE.0b013e3181c928b9.

4. Bathla L, Davies E, Fitzgibbons RJ Jr, Cemaj S. Timing of traumatic lumbar hernia repair: is delayed repair safe? Report of two cases and review of the literature. Hernia 2011; 15 (2):205-209

5. Sol Lee, M.D., Ho Jin Chang, M.D., Lee Hoh Lee, M.D., Young Ran Hong, M.D., Sung Woo Jung, M.D., Seung Ki Kim, M.D. and Chul Woon Chung, M.D Superior Lumbar Hernia J Korean Surg Soc. 2010 Jan;78(1):62-65.

6. Park HR, Baek SK, Lee TS, Bae OS, Park SD. Lumbar hernia combined with descending colon incarceration. J Korean Surg Soc 2006; 71:482-485.
7. Di Carlo I, Toro A, Sparatore F, Corsale G. Lumbar hernia repaired using a new technique. Am Surg. 2007 Jan; 73(1):54-7

8. Adam J. Burick, Salvatore A. Parascandola Laparoscopic Repair of a Traumatic Lumbar Hernia: A Case Report, Journal of Laparoendoscopic Surgery.Aug 1996: 25962.

9. X. Zhou et all; Lumbar hernia: Clinical analysis of 11 cases August 2004, Volume 8, Issue 3, pp 260-263.

10. Stamatiou D, Skandalakis JE, Skandalakis LJ, Mirilas P. Lumbar hernia: surgical anatomy, embryology, and technique of repair. Am Surg. 2009 Mar; 75(3):202-7.

11. Moreno-Egea A, Torralba-Martinez JA, Morales G, Fernández T, Girela E, Aguayo-Albasini JL. Open vs laparoscopic repair of secondary lumbar hernias: a prospective nonrandomized study Surg Endosc. 2005 Feb;19(2):184-7. Epub 2004 Dec 2.

12. Moreno-Egea A, Alcaraz AC, Cuervo MC. Surgical options in lumbar hernia: laparoscopic versus open repair. A longterm prospective study. Surg Innov. 2013 Aug;20(4):331-44. doi: 10.1177/1553350612458726. Epub 2012 Sep 6.

13. Garg CP, Sharma P, Patel G, Malik P. Sutureless meshplasty in lumbar hernia. Surg Innov2011;18(3):285-288

14. Edwards C, Geiger T, Bartow K, Ramaswamy A, Fearing N,Thaler $\mathrm{K}$ et al Laparoscopic trans-peritoneal repair of flank hernias: a retrospective review of 27 patients.Surg Endosc 2009; 23(12): 26922696

15. Carbonell AM, Kercher KW, Sigmon L, Matthews BD, Sing RF, Kneisl JS et al A novel technique of lumbar hernia repair using bone anchor fixation. Hernia 2005; 9(1):22-26 